\section{IMPORTANCIA DE LA EVALUACIÓN EXTERNA DEL DESEMPEÑO EN CITOLOGÍA CERVICOUTERINA: PROGRAMA PILOTO}

\author{
IMPORTANCE OF EXTERNAL QUALITY \\ ASSESSMENT IN CERVICAL CYTOLOGY: A \\ PILOT PROGRAM
}

\author{
María Miraval1,a, Mercy Merejildo ${ }^{1, b}$, \\ María Núñez ${ }^{2, a}$, Carlos Barrionuevo ${ }^{2, a}$, \\ Gustavo Sarria-Bardales ${ }^{2, c}$, Carmen Nuñez ${ }^{2, d}$, \\ Javier Vargas ${ }^{1, e}$
}

Sr. Editor. El cáncer de cérvix constituye un importante problema de salud pública en el mundo. Es el segundo tipo de cáncer más frecuente entre las mujeres y ostenta el primer lugar en muchos países en vías de desarrollo ${ }^{(1)}$. Esta situación se mantiene a pesar que desde hace más de 30 años se utiliza la citología cervicouterina (PAP) como técnica de tamizaje ${ }^{(2)}$ que, si bien ha contribuido en la reducción de la incidencia de cáncer de cérvix en muchos países desarrollados, no se ha observado el mismo efecto en los países en vías de desarrollo. Esto se podría deber a importantes dificultades para alcanzar coberturas adecuadas, garantizar la calidad de la prueba a lo largo de todo el proceso, y lograr un seguimiento apropiado y un tratamiento oportuno de las mujeres con lesiones precancerosas y cáncer invasor. Adicionalmente, casi todos los países muestran considerables deficiencias en sus sistemas de información (2). Son varios los factores que resultan críticos para el éxito de un programa de tamizaje ${ }^{(3)}$; uno muy importante está relacionado con la capacidad que tienen los patólogos y citotecnólogos en hacer una adecuada interpretación de la citología (4).

La calidad de las citologías es un factor relevante que puede estar explicando su bajo impacto en la mortalidad por cáncer de cérvix en los países de América Latina ${ }^{(5)}$. Es en ese contexto es que el Instituto Nacional de Salud (INS) y el Instituto Nacional de Enfermedades Neoplásicas (INEN) plantean el desarrollo de un Programa de

\footnotetext{
Instituto Nacional de Salud. Lima, Perú.

Instituto Nacional de Enfermedades Neoplásicas. Lima, Perú.

a Médico anatomopatólogo; ${ }^{\mathrm{b}}$ tecnólogo médico; ${ }^{\mathrm{c}}$ médico radioterapeuta; ${ }^{\mathrm{d}}$ obstetra ${ }^{\mathrm{e}}$ médico epidemiológo;

Recibido: 06-03-13 Aprobado: 06-03-13
}

Citar como: Miraval M, Merejildo M, Núñez M, Barrionuevo C, Sarria G, Nuñez C, et al. Importancia de la evaluación externa del desempeño en citología cervicouterina: programa piloto [carta]. Rev Peru Med Exp Salud Publica. 2013;30(1):142-3.
Evaluación de Desempeño en Citología Cervicouterina (PEED-Citología) que busca implementar el control de calidad externo a los profesionales y técnicos que tienen la responsabilidad de la lectura de las citologías en los establecimientos de salud de Lima y provincias; siendo su principal objetivo el identificar las carencias y requerimientos de fortalecimiento en las capacidades del personal que realiza estas lecturas, así como promover uniformidad en la nomenclatura y en los criterios de diagnóstico.

Para ello se desarrolló un piloto previo a su implementación a nivel nacional entre noviembre y diciembre de 2012 en la Dirección Regional de Salud (DIRESA) del Callao y la Red San Juan, Villa María del Triunfo de la Dirección de Salud (DISA) Lima Sur; se evaluó un total de diez profesionales entre los que participaron cinco anatomopatólogos, cuatro tecnólogos médicos y un técnico de laboratorio, que realizaban la actividad de lectura citológica cervicouterina. Los paneles que se utilizaron para la evaluación estuvieron conformados por láminas con confirmación histológica y que contaban con un diagnóstico citológico de consenso entre anatomopatólogos del servicio de citología del INEN (comité de expertos). Las categorías diagnósticas que se contemplaron fueron: negativo, inadecuado, lesión escamosa intraepitelial de bajo grado (LEIBG), lesión escamosa intraepitelial de alto grado (LEIAG), carcinoma escamoso invasor y adenocarcinoma. La aplicación de la evaluación se desarrolló en cada centro de labores, durante un periodo de noventa minutos y estuvo a cargo de dos facilitadores (uno del INEN y uno del INS), los evaluados utilizaron el microscopio que habitualmente utilizaban para leer las láminas citológicas. La información fue analizada mediante índices de concordancia global y análisis de concordancia por categoría diagnóstica.

Del total de los resultados evaluados, se encontró una concordancia de $79 \%$ y discordancia de $21 \%$, de los cuales el $8 \%$ correspondían a un subdiagnóstico, y el $13 \%$ a un sobrediagnóstico, con un índice Kappa de 0,73 que corresponde a una buena concordancia. Cuando se hizo el análisis por categoría diagnóstica, se observó un sobrediagnóstico en los siguientes casos: negativo $20 \%$, LEIBG $5 \%$, LEIAG $14 \%$; así como subdiagnóstico en un 10\% de los LEIBG, 10\% de los LEIAG y $18 \%$ de los carcinomas invasores (Tabla 1). Los resultados individuales fueron informados guardando la confidencialidad respectiva, un consolidado fue dirigido a los directores con la finalidad de involucrarlos en las acciones correctivas, de ser necesarias (capacitación de recursos, reevaluación). 
Tabla 1. Evaluación del programa piloto Evaluación Externa del Desempeño en Citología Cervicouterina (PEED-CITOLOGIA) 2012.

\begin{tabular}{lccc}
\hline & $\begin{array}{c}\text { Concordancia } \\
\text { observada (\%) }\end{array}$ & $\begin{array}{c}\text { Sobre- } \\
\text { diagnóstico } \\
(\%)\end{array}$ & $\begin{array}{c}\text { Sub- } \\
\text { diagnóstico } \\
(\%)\end{array}$ \\
\hline Negativo & 76,7 & 20,0 & 3,3 \\
LEIBG & 85,0 & 5,0 & 10,0 \\
LEIAG & 75,9 & 13,8 & 10,3 \\
Carcinoma & 81,8 & 0,0 & 18,2 \\
invasor & &
\end{tabular}

LEIBG: lesión escamosa intraepitelial de bajo grado.

LEIAG: lesión escamosa intraepitelial de alto grado.

Nota: se evaluó la concordancia de diez responsables de lectura citológica sobre un panel conformado por diez láminas.

Lo relevante corresponde a los subdiagnósticos de LEIAG y de carcinoma invasor. En el primer caso, las LEIAG fueron diagnosticadas como LEIBG y ASCUS, lo que implica un procedimiento médico diferente del que le corresponde, ya que para los casos de LEIAG el protocolo indica hacer una biopsia dirigida, cono frio, electrocirugía o histerectomía ampliada dependiendo de la expectativa de fertilidad de la paciente ${ }^{(6)}$, mientras que para la LEIBG y ASCUS corresponde seguimiento mediante PAP/IVAA/ colposcopia cada seis meses durante dos años ${ }^{(6)}$. En el caso del carcinoma invasor, uno de ellos fue diagnosticado como LEIBG que, según los protocolos establecidos, requiere de observación y control cada seis meses.

Dado que el panel estaba conformado por diez láminas y fueron evaluados diez responsables de lectura citológica, el ámbito del piloto fue de cien diagnósticos lo que hace un $4 \%$ (cuatro casos) en los que la discordancia implica un procedimiento médico hacia la paciente, diferente del que le correspondía. Consideramos que la aplicación del PEED Citología a nivel nacional permitirá mejorar el servicio de lectura de citología cervicouterina que se brinda a las usuarias, ayudando a reducir el porcentaje de subdiagnósticos; lo que también permitirá a los establecimientos de salud que brindan este servicio conocer su nivel de desempeño a fin de involucrarse en un proceso de mejora continua hasta alcanzar niveles óptimos, con la consecuente mejora en la atención a la población.

Fuentes de financiamiento: el desarrollo del Piloto PEEDCitología ha sido desarrollado con financiamiento del Centro Nacional de Salud Pública del Instituto Nacional de Salud y del Instituto Nacional de Enfermedades Neoplásicas.

\section{REFERENCIAS BIBLIOGRÁFICAS}

1. Organización Mundial de la Salud. Prevención de las enfermedades crónicas. Una inversión total. Ginebra: OMS; 2005.

2. Organización Panamericana de la Salud. Situación de los programas para la prevención y el control del cáncer cervicouterino: evaluación rápida mediante encuesta en doce países de América Latina. Washington, DC: OPS; 2010.

3. Madlensky A, Goel V, Polzar J, Ashbury FD. Assesing the evidence for organized cancer screening programmes. Eur J Cancer. 2003;39(12):1648-53.

4. Miller A, Goel V. Screening. En: Detels R, McEwen J, Beaglehole R, Tanaka H, editors. Oxford Textbook of Public Health. The Methods of Public Health. Fourth edition. Oxford: Oxford University Press; 2002.

5. Cendales R, Wiesner C, Murillo R, Piñeros M, Tovar S, Mejía J. La calidad de las citologías para tamización de cáncer de cuello uterino en cuatro departamentos de Colombia: un estudio de concordancia. Biomédica. 2010;30(1):107-15

6. Coalición Multisectorial "Perú contra el Cáncer". Norma técnico-oncológica para la prevención, detección y manejo de las lesiones premalignas del cuello uterino a nivel nacional. Lima: Instituto Nacional de Enfermedades Neoplásicas; 2008

Correspondencia: María Luz Miraval Toledo

Dirección: Calle Cápac Yupanqui 1400. Lima 33, Perú.

Teléfono: (511) 7481111 Anexo 2110

Correoelectrónico:mmiraval@ins.gob.pe

\section{NECESIDAD DE FORTALECER EL SISTEMA DE SALUD ANTES DE LA IMPLEMENTACIÓN DE LA VACUNA CONTRA EL VIRUS DEL PAPILOMA HUMANO}

\author{
THE NEED TO STRENGTHEN THE HEALTH \\ SYSTEM BEFORE THE IMPLEMENTATION \\ OF THE VACCINE AGAINST THE HUMAN \\ PAPILLOMAVIRUS
}

\author{
Juan J. Montenegro-Idrogo $0^{1, a}$, \\ Carla Young-Candia ${ }^{1, a}$, Mariana Ramos ${ }^{1, b}$
}

Sr. Editor. Las estrategias de prevención y control de cáncer de cérvix (CC), especialmente el tamizaje de Papanicolaou (PAP), han sido objeto de varios estudios que han evaluado desde su efectividad hasta su impacto cultural en poblaciones latinoamericanas $(1,2)$. En la actualidad, el debate está centrado en la introducción de la vacuna contra el virus del papiloma humano (VPH) como profilaxis. Si bien es difícil la implementación de la vacuna,

\footnotetext{
Sociedad Científica San Fernando, Facultad de Medicina "San Fernando", Universidad Nacional Mayor de San Marcos. Lima, Perú.

Estudiante de Medicina; ${ }^{\mathrm{b}}$ médico epidemióloga

Recibido: 25-02-13 Aprobado: 06-03-13
}

Citar como: Montenegro-Idrogo JJ, Young-Candia C, Ramos M. Necesidad de fortalecer el sistema de salud antes de la implementación de la vacuna contra el virus del papiloma humano [carta]. Rev Peru Med Exp Salud Publica. 2013;30(1):143-4. 